\title{
Penggunaan pupuk organik cair sebagai pengganti pupuk kimia di Desa Sidomulyo, Kecamatan Air Naningan
}

\author{
Naufal Dani Fauzan ${ }^{1}$, Ardan Maulana ${ }^{1}$, Izzah Safina An-Najjah ${ }^{1}$, Fattur Rachman ${ }^{2}$, Erninda \\ Octalyani $^{3}$
}

\begin{abstract}
Maintaining soil health is very important on cultivated land in order to increase plant productivity. The effect of using inorganic fertilizers (chemical fertilizers) in the long term causes the soil organic matter to decrease, the soil structure is damaged, and environmental pollution. Rice waste on a household scale, especially stale rice, is increasing as the population increases. The availability of sources of organic matter in the surrounding environment which is still not optimally utilized, only becomes waste. To overcome this problem, counseling was made on the manufacture of $\mathrm{MOL}$ rice and liquid organic fertilizer as a substitute for chemical fertilizers. The manufacturing activity uses raw materials that are easily found in the surrounding environment, namely stale rice, rice washing water, Moringa leaves, banana weevil, coconut husk, aloe vera, and brown sugar. It is hoped that the manufacture of MOL Rice and Liquid Organic Fertilizer can easily be imitated by farmers and can reduce costs due to the high price of chemical fertilizers. Based on the dedication that has been done, the farmers are very enthusiastic in participating in extension activities and the application of making MOL and liquid organic fertilizers and there is growing awareness among farmers about the negative impact of using artificial fertilizers.
\end{abstract}

\section{Keywords}

LM of Rice, Liquid Organic Fertilizer, Chemical Fertilizer

\section{Pendahuluan}

Desa Sidomulyo merupakan salah satu desa yang berada di Kecamatan Air Naningan, Kabupaten Tanggamus, Provinsi Lampung. Mayoritas penduduk Desa Sidomulyo berprofesi sebagai petani dengan komoditas andalan yaitu kakao, lada, kopi, dan pisang. Produksi kopi di kecamatan Air Naningan mengalami penurunan yang sangat signifikan pada tahun 2018 sebesar 8.766 ton menjadi 4.500 ton di tahun 2019 (BPS Kabupaten Tanggamus, 2020). Penurunan produksi kopi salah satu penyebabnya adalah kondisi tanah yang tidak subur yang diakibatkan degradasi tanah karena model penggunaan lahan yang intensif, serta penggunaan input kimiawi seperti pupuk pestisida dan herbisida (Eswaran et al., 1993). Petani di desa Sidomulyo menggunakan pupuk kimia dalam pemenuhuhan unsur hara yang dibutuhkan oleh tanaman, sedangkan menurut Isnaini (2006) penggunaan pupuk anorganik (pupuk kimia) dalam jangka panjang menyebabkan kadar bahan organik tanah menurun, struktur tanah rusak, dan pencemaran lingkungan. Hal ini jika terus berlanjut akan menurunkan kualitas tanah dan kesehatan lingkungan.

Petani memerlukan pupuk organik cair yaitu karena untuk mendapatkan pupuk kimia petani sering mengalami keterlambatan sehingga pertumbuhan tanaman menjadi terhambat karena waktu pemupukan tidak tepat sehingga produksi tanaman menjadi menurun. Pupuk organik cair memiliki banyak keunggulan bila dibandingkan dengan kompos padat. Pupuk cair lebih cepat meresap ke dalam tanah dan diserap oleh tanaman, lebih praktis digunakan dan proses pembuatannya lebih cepat 2-3 minggu (Pratama $\&$ Irianto, 2020).

Hampir semua limbah rumah tangga menghasilkan sampah organik berupa nasi basi. Meskipun dalam jumlah sedikit nasi basi dapat dimanfaatkan sebagai bahan untuk membuat Mikroorganisme Lokal (MOL). Menurut Arfian $\mathrm{dkk}$. Jenis mikroba yang yang terkandung dalam MOL nasi basi adalah Sachharomyces cerevicia dan Aspergillus sp. yang berperan dalam proses pengomposan.

Pupuk organik cair yang digunakan menggunakan bahan baku yang mudah didapatkan di lingkungan sekitar yaitu daun kelor, bonggol pisang, dan sabut kelapa. Daun kelor

\footnotetext{
${ }^{1}$ Jurusan Agronomi dan Hortikultura, Universitas Lampung ${ }^{2}$ Jurusan IImu Tanah, Universitas Lampung ${ }^{3}$ Jurusan Agroteknologi, Universitas Lampung

Korespondensi:

Naufal Dani Fauzan, Jurusan Agronomi dan Hortikultura, Universitas Lampung

Email: naufaldani1201@gmail.com
} 
mengandung unsur makro, yaitu kalsium sebesar 3.65\%, potasium sebesar $1.50 \%$ dan fosfor sebesar $0.30 \%$ (Chandi, 2018). Menurut Maspary (2012), di dalam bonggol pisang terdapat zat pengatur tumbuh giberellin dan sitokinin, serta terdapat 7 mikroorganisme yang sangat berguna bagi tanaman yaitu Azospirillium, Azotobacter, Bacillus, Aeromonas, Aspergillus, mikroba pelarut phospat dan mikroba selulotik yang dapat dimanfaatkan sebagai pupuk cair. Di dalam sabut kelapa terkandung unsurunsur hara dari alam yang sangat dibutuhkan tanaman yaitu kalium(K), selain itu juga terdapat kandungan unsur-unsur lain seperti kalsium $(\mathrm{Ca})$, magnesium $(\mathrm{Mg})$, natrium $(\mathrm{Na})$ dan fosfor(P) (Sari, 2015).

Penggunaan pupuk organik cair yang dibantu dengan MOL nasi yang dibuat oleh para petani di Desa Sidomulyo selain dapat memanfaatkan bahan organik yang ada disekitar, diharapkan dapat meningkatkan produksi semua komoditas yang dibudidayakan oleh petani. Selain itu diharapkan pupuk organik cair dapat mengurangi ketergantungan petani terhadap penggunaan pupuk kimia sehingga budidaya tanaman akan mengarah pada sistem pertanian yang berkelanjutan.

\section{Metode}

Kegiatan pengabdian masyarakat ini dilakukan bulan Februari 2020 (sebelum pandemi Covid-19 menyebar di Indonesia) di Desa Sidomulyo, Kecamatan Air Naningan, Kabupaten Tanggamus. Bahan yang digunakan dalam proses pembuatan pupuk organik cair adalah nasi basi, air cucian beras, daun kelor, bonggol pisang, sabut kelapa, lidah buaya, dan gula merah. Alat yang digunakan adalah pisau dan wadah tertutup. Sebelum kegiatan penyuluhan dilakukan, kami melakukan observasi ke beberapa lahan petani untuk mengetahui kondisi tanaman budidaya.

Selanjutnya dilakukan pelaksanaan penyuluhan diawali dengan penyampaian materi tentang berbagai macam pupuk organik dan pentingnya penggunaan pupuk organik cair terhadap peningkatan produksi, serta mekanisme pembuatan pupuk organik cair hingga siap untuk diaplikasikan. Setelah penyampaian materi selesai dilanjutkan dengan praktik pembuatan pupuk organik cair yang telah disiapkan alat dan bahannya sambil diberi penjelasan secara singkat. Praktik pembuatan POC usai dilanjutkan dengan sesi diskusi dengan para petani disertai dengan sharing permasalahan yang ada di lahan perkebunan.

Kegiatan peninjauan pembuatan pupuk organik cair dan MOL dilakukan di beberapa anggota yang sudah menerapkannya di rumah masing-masing. Hal tersebut dilakukan untuk mengetahui tingkat keberhasilan penyuluhan dengan mengidentifikasi hasil pembuatan pupuk organic cair dengan indikator aroma pupuk seperti bau asam tapai.

\section{Hasil}

\section{Penyampaian materi pembuatan Pupuk Organik Cair}

Sebelum dilakukan kegiatan penyuluhan dan praktik pembuatan pupuk organik cair, kami melakukan koordinasi terlebih dahulu kepada para ketua kelompok tani untuk memberitahukan kepada para anggotanya untuk menghadiri kegiatan tersebut. Fungsi dari koordinasi untuk menentukan jadwal kegiatan yang tepat sehingga diharapkan para petani lebih banyak datang saat kegiatan berlangsung. Hal tersebut sesuai dengan Simonangkir (2012) mengemukakan bahwa koordinasi adalah proses penyatupaduan sasaran-sasaran dan kegiatan-kegiatan dari unit-unit yang terpisah untuk mencapai tujuan organisasi secara efisien.

Kegiatan penyampaian materi diawali dengan pengenalan petani terhadap jenis-jenis pupuk organik yang dapat dimanfaatkan sebagai pengganti pupuk kimia. Setelah itu dilanjutkan dengan penyampaian prosedur pembuatan mol nasi basi dan pembuatan pupuk organik cair secara datail. Materi yang disampaikan disesuaikan dengan kebiasaan masyarakat disana agar mudah dipahami dan dapat diterima sehingga memungkinkan petani dapat mengaplikasikannya dalam budidaya tanaman masing-masing.

\section{Praktik Pembuatan MOL Nasi dan Pupuk Organik Cair}

Pembuatan mol nasi diawali dengan penyiapan nasi yang telah didiamkan selama satu minggu sehingga berjamur. Nasi basi yang telah berjamur di hancurkan agar proses fermentasi dapat berjalan secara merata. Air cucian beras yang telah disiapkan dicampur dengan gula merah yang telah dilarutkan dengan air dan diaduk hingga merata. Campuran tersebut dimasukkan nasi basi yang telah dihancurkan dan diaduk kembali dan didiamkan selama 13 hari. Waktu tersebut menghasilkan kandungan terbaik dibandingakan 10 dan 16 hari (Meriatna et al., 2018). Pembuatan mol nasi dilakukan sebelum

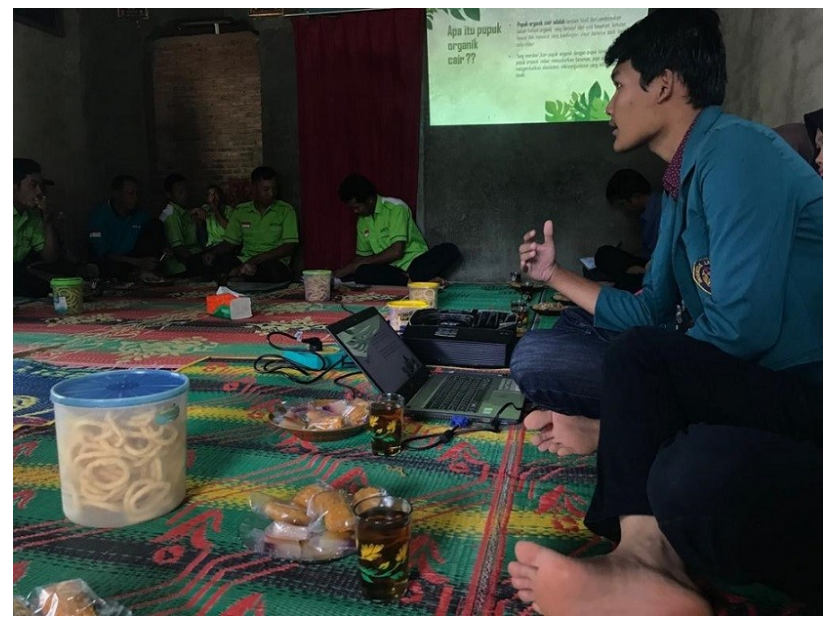

Gambar 1. Penyampaian materi pembuatan MOL dan POC 


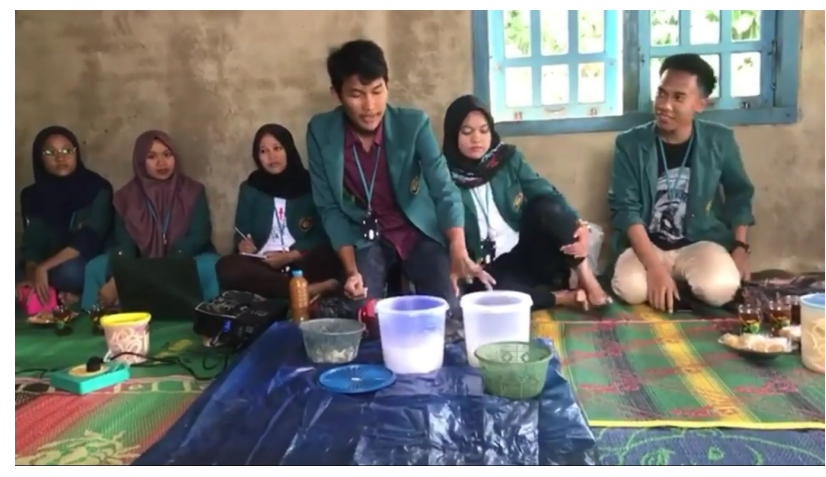

Gambar 2. Praktik Pembuatan MOL nasi dan POC

kegiatan penyuluhan dan praktik untuk mempersingkat waktu, namun ketika kegiatan penyuluhan tetap dilakukan praktik pembuatan mol nasi untuk menambah pemahaman terhadap petani. Mol nasi yang telah jadi memiliki bau asam seperti tapai, hal tersebut diperkuat oleh Rahmah et al. (2014) yang menyatakan bahwa mikro organisme yang terkandung dalam MOL akan melakukan fermentasi bahan-bahan organik sehingga menghasilkan asam organik yang berbau asam seperti tapai.

Pembuatan pupuk organik cair dimulai dengan mencampurkan air cucian beras dan gula merah cair dilanjutkan penambahan mol nasi yang telah dibuat sebelumnya kemudian diaduk hingga homogen. Bahan utama berupa daun kelor, bonggol pisang, sabut kelapa dan lidah buaya dipotong atau dicacah terlebih dahulu agar mempercepat proses fermentasi. Ketiga bahan tersebut dimasukkan ke dalam campuran larutan gula dan cucian beras serta diaduk kembali menjadi homogen. Larutan yang telah tercampur di tutup rapat dan di diamkan selama 14 hari hingga pupuk organik cair siap diaplikasikan. Setiap hari dilakukan pengecekan dan wadah dibuka untuk melepas gas $\mathrm{CO} 2$ yang terperangkap.

\section{Diskusi dan Sharing Permasalahan yang ada di Perkebunan}

Terdapat pertanyaan dari seorang petani masih mempertanyakan tingkat efektifitas dari penggunaan pupuk organik cair tersebut terhadap pupuk kimia. Beliau beranggapan bahwa pupuk organik memiliki respon yang lambat terhadap pertumbuhan tanaman sehingga kurang baik terhadap pertumbuhan tanaman. Sedangkan menurut Inrianti et al. (2019) penggunaan pupuk organik cair dapat meningkatkan produksi tanaman dan menjaga keseimbangan hara pada tanah, serta baik bagi lingkungan karena tidak menyebabkan pencemaran lingkungan serta menyediakan mikroorganisme bagi tanah.

\section{Peninjauan Hasil Penuluhan dan Praktik}

Setelah kegiatan penyuluhan usai dilakukan pengecekan terhadap keberhasilan petani dalam memahami prosedur pembuatan pupuk organik cair yang benar. Pada peninjauan yang telah dilakukan petani sudah berhasil membuat pupuk organik cair sesuai standar dengan ciri-ciri aroma pupuk berbau asam seperti tapai. Petani juga telah berinisiatif mencobanya di lahan perkebunan masing-masing meskipun hasilnya tidak langsung terlihat.

\section{Kesimpulan}

Berdasarkan penyuluhan yang telah dilakukan para petani sangat antusias dalam mengikuti kegiatan penyuluhan dan aplikasi pembuatan MOL dan pupuk organik cair di rumah masing-masing. Telah tumbuh kesadaran pada petani akan dampak negatif penggunaan pupuk buatan dan sarana pertanian modern lainnya terhadap lingkungan pada sebagian kecil petani telah membuat mereka beralih dari pertanian konvensional ke pertanian yang ramah lingkungan. Diharapkan agar dapat dilakukan kegiatan penyuluhan dan pendampingan terkait pertanian organik oleh stakeholder atau instansi terkait sehingga para petani di Desa Sidomulyo, Kecamatan Air Naningan dapat menerapkan lebih baik lagi.

\section{Referensi}

Arifan, F., Setyati, W. A., Broto, R. T. W., dan Dewi, A. L. 2020. Pemanfaatan nasi basi sebagai mikro organisme lokal (MOL) untuk pembuatan pupuk cair organik di Desa Mendongan Kecamatan Sumowono Kabupaten Semarang. Jurnal Pengabdian Vokasi. 1 (4) 252-255

BPS Kabupaten Tanggamus. 2020. Produksi Tanaman Perkebunan 2018-2019. https://tanggamuskab.bps.go.id (Diakses 21 Maret 2021)

Chandi, T. A. 2018. Panen dan Pasca Panen Kelor ( Moringa Oleifera Lam ) Organik Di PT Moringa Organik Indonesia Blora Jawa Tengah. Institut Pertanian Bogor. Bogor

Eswaran, H., S.M.Virmani \& L.D. Spivey Jr. 1993. Sustainable Agriculture In Developing Countries: Contraints, Chalanges and Choices.pp 7-24. In J. Ragland \& R. Lal- (Eds) Technologgies for Sustainable Agriculture in the Tropics. ASA Spec. Pub. No. 56. ASACSSA-SSSA.

Inrianti, Tuhuteru, S., dan Paling, S. 2019. Pembuatan mikroorganisme lokal bonggol pisang pada kelompok tani tunas harapan Distrik Walelagama, Jayawijaya, Papua. Agrokreatif 5(3): 188-194.

Isnaini,M. 2006. Pertanian Organik. Cetakan Pertama.Yogyakarta : Penerbit Kreasi Wacana.

Maspary. 2012. Apa Kehebatan MOL Bonggol Pisang. Gramedia. Jakarta

Meriatna, Suryati, dan Fahri, A. 2018. Pengaruh waktu fermentasi dan volume bio aktivator EM4 (Effective Microorganisme) pada pembuatan pupuk organik cair (POC) dari limbah buahbuahan. Jurnal Teknologi Unimal. 7(1): 13-29

Pratama, dan Triyanto. 2020. Membuat Pupuk Organik Cair dengan Mudah. Elex Media Komputindo. Jakarta. 
Rahmah, A., M. Izzati dan S. Parman. 2014. Pengaruh pupuk organik cair berbahan dasar limbah sawi putih (Brassica chinensis L.) terhadap pertumbuhan tanaman jagung manis (Zea mays L. var. Saccharata). J. Anatomi dan Fisiologi, 22 (1) : $65-71$.
Sari, S.Y. 2015. Pengaruh Volume Pupuk Organik Cair Berbahan Dasar Serabut Kelapa(Cocos nucifera) Terhadap Pertumbuhan dan Hasil Panen Sawi Hijau(Brassica juncea). Skripsi. Universitas Sanata Dharma, Yogyakarta.

Simonangkir, I. 2012. Koordinasi dan Interaksi Kebijakan Fiskal Moneter: Tantangan Kedepan. Kanisius. Yogyakarta. 